\title{
S5 Table
}

Livers WITH gallbladders.

\begin{tabular}{|c|c|c|c|c|c|c|c|c|c|}
\hline $\begin{array}{l}\text { cadaver } \\
\text { number }\end{array}$ & $\begin{array}{l}\text { Age } \\
\text { (yrs) }\end{array}$ & Sex & $\begin{array}{l}\text { weight } \\
\text { of fossa } \\
\text { mold } \\
(\mathrm{g})\end{array}$ & $\begin{array}{l}\text { Calculated } \\
\text { volume of } \\
\text { fossa }(\mathrm{ml})\end{array}$ & $\begin{array}{l}\text { Depth } \\
\text { of } \\
\text { fossa } \\
\text { mold } \\
(\mathrm{mm}) \\
\end{array}$ & $\begin{array}{l}\text { Length } \\
\text { of } \\
\text { fossa } \\
\text { mold } \\
(\mathrm{mm}) \\
\end{array}$ & $\begin{array}{l}\text { Width } \\
\text { of } \\
\text { fossa } \\
\text { mold } \\
(\mathrm{mm}) \\
\end{array}$ & $\begin{array}{c}\text { Liver } \\
\text { weight } \\
(\mathrm{g})\end{array}$ & $\begin{array}{c}\text { Femur } \\
\text { length } \\
(\mathrm{mm}) \\
\end{array}$ \\
\hline 1 & 80 & $\mathrm{M}$ & 0.886 & 34.88 & 21.03 & 54.09 & 50.40 & 752 & 435 \\
\hline 3 & 72 & $\mathrm{M}$ & 0.573 & 22.56 & 29.53 & 57.21 & 33.30 & 1164.2 & 482 \\
\hline 4 & 105 & $\mathrm{~F}$ & 1.671 & 65.79 & 29.97 & 86.16 & 54.17 & 820 & 411 \\
\hline 7 & 92 & $\mathrm{~F}$ & 0.61 & 24.02 & 10.89 & 55.06 & 50.47 & 1138.9 & 431 \\
\hline 8 & 92 & $M$ & 0.783 & 30.83 & 24.23 & 63.71 & 70.68 & 1333 & 464 \\
\hline 10 & 80 & $\mathrm{~F}$ & 0.445 & 17.52 & 17.59 & 48.99 & 51.73 & 1082.5 & 479 \\
\hline 11 & 75 & $\mathrm{M}$ & 1.004 & 39.53 & 21.94 & 73.23 & 59.45 & 2013.1 & 447 \\
\hline 12 & 67 & $\mathrm{~F}$ & 0.741 & 29.17 & 22.88 & 76.36 & 45.29 & 984.5 & 440 \\
\hline 13 & 89 & $\mathrm{~F}$ & 0.994 & 39.13 & 26.38 & 54.58 & 67.97 & 648.1 & 414 \\
\hline 14 & 91 & $\mathrm{M}$ & 0.922 & 36.30 & 22.32 & 78.29 & 46.55 & 1072.7 & 497 \\
\hline 15 & 93 & $\mathrm{~F}$ & 0.256 & 10.08 & 14.87 & 52.70 & 40.31 & 1011 & 420 \\
\hline 16 & 84 & $F$ & 0.456 & 17.95 & 20.37 & 74.11 & 34.51 & 778.7 & 403 \\
\hline 17 & 76 & $\mathrm{M}$ & 0.65 & 25.59 & 19.31 & 78.11 & 47.99 & 1871.2 & 445 \\
\hline 19 & 90 & $\mathrm{M}$ & 0.899 & 35.39 & 24.19 & 61.74 & 50.43 & 1242.4 & 479 \\
\hline 20 & 87 & $\mathrm{~F}$ & 0.49 & 19.29 & 14.06 & 50.25 & 78.49 & 961.8 & 461 \\
\hline 21 & 93 & $\mathrm{M}$ & 2.331 & 91.77 & 36.97 & 67.65 & 79.24 & 1061.4 & 493 \\
\hline 22 & 71 & $\mathrm{M}$ & 1.226 & 48.27 & 24.85 & 92.72 & 55.25 & 1553.6 & 502 \\
\hline 24 & 67 & $\mathrm{M}$ & 1.038 & 40.87 & 25.95 & 70.44 & 47.62 & 1323.4 & 470 \\
\hline 25 & 60 & $\mathrm{~F}$ & 0.832 & 32.76 & 24.53 & 58.77 & 59.72 & 729.5 & 402 \\
\hline 26 & 90 & $\mathrm{M}$ & 0.714 & 28.11 & 18.83 & 69.44 & 45.27 & 731.6 & 466 \\
\hline 27 & 88 & $\mathrm{~F}$ & 0.299 & 11.77 & 13.24 & 64.46 & 42.02 & 918 & 420 \\
\hline 29 & 104 & $\mathrm{~F}$ & 0.183 & 7.20 & 17.03 & 34.89 & 36.86 & 838.6 & 386 \\
\hline 30 & 74 & $\mathrm{M}$ & 0.905 & 35.63 & 19.42 & 77.93 & 50.33 & 1122.8 & 504 \\
\hline 31 & 95 & $\mathrm{~F}$ & 0.525 & 20.67 & 24.36 & 59.77 & 49.35 & 838.1 & 453 \\
\hline 32 & 73 & $\mathrm{M}$ & 0.677 & 26.65 & 20.00 & 63.48 & 45.98 & 1051.9 & 483 \\
\hline 35 & 100 & $\mathrm{~F}$ & 0.371 & 14.61 & 9.98 & 66.79 & 42.79 & 942.6 & 424 \\
\hline
\end{tabular}

